\title{
Modeling the population and industry distribution impacts of urban land use policies in Beijing
}

\author{
Niu Fangqu ${ }^{\mathrm{a}}$, Li Jun ${ }^{\mathrm{b}, *}$ \\ a Institute of Geographic Sciences and Natural Resources Research, Chinese Academy of Sciences, Beijing 1001, China \\ ${ }^{\mathrm{b}}$ School of Mathematics and Computer Science, Faculty of Science and Engineering, University of Wolverhampton, Wolverhampton WV1 1LY, UK
}

\section{A R T I C L E I N F O}

\section{Keywords:}

Urban evolution

LUTI

Accessibility

Forecast

Urban planning

Sustainability

\begin{abstract}
A B S T R A C T
Capable tools are desired for urban spatial policies planning in China to safeguard its sustainable development strategy. This study develops an activity-based Land Use/Transport Interaction (LUTI) model to forecast the urban activity impacts of the land-use policies. Essentially, its endogenized and interactive features in residential and employment distribution modeling mark it out from the traditional Lowry models. The LUTI model proposed consists of four models, i.e., a transport sub-model, a residential location model, an employment location model and a real estate rent model. It is then applied to the Beijing metropolitan area to characterize the urban activity evolution trend under the land use policies of recent years. The results show that with the increasing number of floorspace developed on the outskirts, more residents and employers are relocating there and sub-centers are formed to divide the service of central Beijing. This trend is consistent with the objective of government planning to develop more sub-centers around central Beijing by decentralizing industries to guide residential population growth patterns. The model provides a capable planning tool for urban spatial policy makers and demonstrates its first success in Beijing scenario.
\end{abstract}

\section{Introduction}

The present study addresses the issue of urban development from the perspective of the spatial evaluation of urban activities. China has been undergoing a period of rapid and large-scale urban development (Gu and Pang, 2009; Liu et al., 2012). This ongoing process has resulted in increasing adverse effects for environmental and social systems. As a result, urban sustainable development has become one of the most widely discussed issues in urban studies in China. A new type of urbanization strategy in China is now being implemented, intended to bring more people into cities. In this context, urban planners are seeking scientific urban spatial polices for sustainable development. As such, modeling the impacts of urban spatial policies is of great significance for China's decision-makers to develop sustainable development policies.

There is a long tradition of modeling urban growth and development processes in geographic and urban studies. Urban spatial development has historically been focusing on key dynamics or driving forces, key factors, characteristics, effects and trends (Zeng et al., 2015; Haregeweyn et al., 2012; Liu et al., 2012; Liu et al., 2011; Verburg et al., 2009). In China, the most commonly used methods for modeling urban spatial development are Cellular Automata (CA) based models for urban land-use change analysis. The CA-based models mainly concentrate on urban morphology (Deep and Saklani, 2014; Long et al., 2013; Wang et al., 2013; Lagarias, 2012). The corresponding data mainly used is survey land-use data, satellite remote sensing data (Wang et al., 2013; Powers et al., 2015; Jing and Jianzhong, 2011) and physical land use statistics.

However, the rules of interaction between urban activities through transport systems have been studied to a lesser degree, though there are intensive interactions between transport activities and land use planning decisions (Reisi et al., 2016). Besides, there is significant potential and need for enhanced modeling research on changes in the spatial distribution of urban activities in China, where social and economic activities are the essence of a city's development. China's economic reforms have empowered the growth-oriented local governments. Urban land has become a central concern of governmental officials for local economic growth and even rent seeking (Gao et al., 2014; Wei, 2012; Ding and Lichtenberg, 2011). While the urban development and specialization is influenced by state priorities for certain types of development (Zhang, 2000; Liao and Wei, 2014), as a result, the government, not simply the marketplace, has a responsibility for land use change. In this context, a model to forecast urban development trends in terms of the spatial pattern of urban activities is required.

\footnotetext{
* Corresponding author.

E-mail address: Jun.Li@wlv.ac.uk (J. Li).
} 
A city comprises a diverse range of activities, and the evaluation of how these activities spatially interact with each other through transport is an important piece of understanding urban development. As a result of this interaction between activities and transport, the concentration and spatial distribution of activities changes continuously with the urban development. The urban land use/transport interaction model (LUTI) has proven to be an important and effective tool to model the interaction process (Geurs and Wee, 2004; Pierlugi et al., 2013).

Lowry gravity land use model (Wang, 2014; Garin, 1966; Lowry, 1964) as an equilibrium model was one of the first LUTI models. The model estimates and allocates the regional retail employment, residential population and land use to sub-areas within a bounded region through the interactions between the land-use and transport systems driven by gravity formulation. However in practice the drawing boundary between basic and non-basic sectors is not straight forward, especially for large cities such as Beijing. Additionally, the model assumes the basic sectors' locations are exogenous while the decisions on the selections are always influenced by the local residents and sectors. The alternative category in LUTI models is economic models, essentially based on the theory of consumers' behaviour and firm in utility or profit maximization (Wilson, 1998). Contrary to the gravity-based models, utility-based economic models capture the complex choice behavior dynamics involved in land-use and transport decisions at the individual level and address the locational characteristics (Acheampong and Silva, 2015; McFadden, 1978). Complexity theory and general systems theory based on agent-based approaches to model cities as complex adaptive systems have also been introduced into the field of LUTI modelling (Batty, 2007).

Though with the merits of these, few studies in China focus on the LUTI model and there are still no successful applications of LUTI to support decision making to the best of our knowledge. The development of the state-of-the-art LUTI model has a long history and is considered to be activity related (Pierlugi et al., 2013; Brandi et al., 2014) though an activity-based LUTI model is never put into practice. Under this background, based on both Lowry gravity type of models and economic type of models, we develop an employment and household activity-based LUTI model, taking the Beijing metropolitan area as a study case to model urban activity impacts of land-use policies.

The paper proceeds as follows: Section 2 provides a brief review of the literature of the LUTI model and describes the new model in detail. This is followed in Section 3 by an application of the model to evaluate the impacts of land-use policies in Beijing. Section 4 describes the main results, outcomes and further research.

\section{The model development and case study}

\subsection{Overview the LUTI model and rationale}

LUTI models combine theory, data and algorithms to provide an abstract representation of the interaction between the two main components of urban areas: the transport and land use subsystems (Torrens, 2000). The term 'land-use' in LUTI models does not refer to the physical use of land by buildings or transport infrastructure, instead, it tends to refer to the social and economic activities which use space, in particular, where people live and work. In many cases, the space is measured in terms of the quantities of floor space rather than land (Simmonds and Feldman, 2011). A LUTI model is essentially a land-use model linked to a transport model in such a way that each one influences the other. The land-use (represented by population and employment etc. activities) forecast by the land-use model is used by the transport model to generate the demands for transport. Similarly, the travel costs and times forecast by the transport model resulting from the interaction between those demands for transport and the supply of transport are used in the land-use model in calculating accessibilities which, to some extent, influence subsequent land-use changes.

LUTI models have traditionally been used to simulate the possible effects of introducing new policies and projects into existing urban systems and, especially, those related to transport (Zondag et al., 2015; Mohammed, 2014; Foot, 1981). There are quite a few LUTI models that have been developed. The model proposed by Lowry (1964) is a classic LUTI model and was a milestone in the development of LUTI modeling techniques. Later on there were a number of different LUTI models in terms of their objectives and implementation. Wegener (2004), Waddell et al. (2007), Iacono et al. (2008), Timmermans (2003) and Pierlugi et al. (2013) have classified LUTI models found in the literature based on different criteria. Beyond urban planning policy applications, LUTI models are increasingly used in sustainability analysis (Kenji and Masanobu, 2012).

This study develops a LUTI model concentrating on the interaction between residential activities and employment activities to analyze the impacts of urban land use. In contrast to the Lowry model based on the distinction between basic sector and non-basic section, the model is developed by activity.The model assumes that the location/relocation of every activity is based on the ability to maximize their utility/profits, which is affected by real estate rent and accessibility etc., therefore, the change of location utility causes the change of activity distribution. An estate rent model is developed to adjust the rent in an iteration of the modeling.

\subsection{Beijing Land Use/Transport Interaction Model}

\subsubsection{Model description}

The activity-based model is named Beijing Land Use/Transport Interaction Model (BJLUTI), with a target of primary use in China's Beijing metropolitan area. However it can be applied to other cities with minor adjustment.

Traditionally in a Lowry model the non-basic sector employment and local population are shaped by the pattern of basic employment, and thus leaving no option but an exogenously-given residential pattern, whereas for Beijing scenario, the residential land uses are tightly planned by the government. Therefore the BJLUTI model adopts an activity-based approach. The BJLUTI model estimates variations in the location of urban activities including household and employment activities to forecast the spatial pattern of urban activities when faced with changes that are associated with the land use system or transport system, such as the introduction of new land use policies or new transport modes. Directly, the residential distribution is determined by residential land uses planned by government, residential location cost and the transport accessibility; the employment distribution is endogenously determined by commercial rent cost and the destination accessibility. Indirectly, the residential distribution and the employment distribution influence each other and evolve at a dynamic equilibrium. The model mainly concentrates on the interaction between residential activities (i.e., housing) and workplace (i.e., employment) in terms of work commuting.

The transport model calculates accessibility by zone based on the transport network and the spatial distribution of urban activities. The land use model calculates the location of activities based on accessibility from the transport model and other factors including land use policies (Fig. 1). The interaction between the sub-models is solved through an equilibrium solution, that is, any change occurring in the territorial system to lead to a new equilibrium solution representing the new state of the system.

\subsubsection{BJLUTI model components}

The integrated system is made up of four interrelated sub-models: a transport model, a residential location model, an employment location model, and an implicit rent adjusted model. Each sub-model is illustrated in detail below.

2.2.2.1. Transport model. Here the transport model adopts an exponential distance decay function instead of the power function, as 


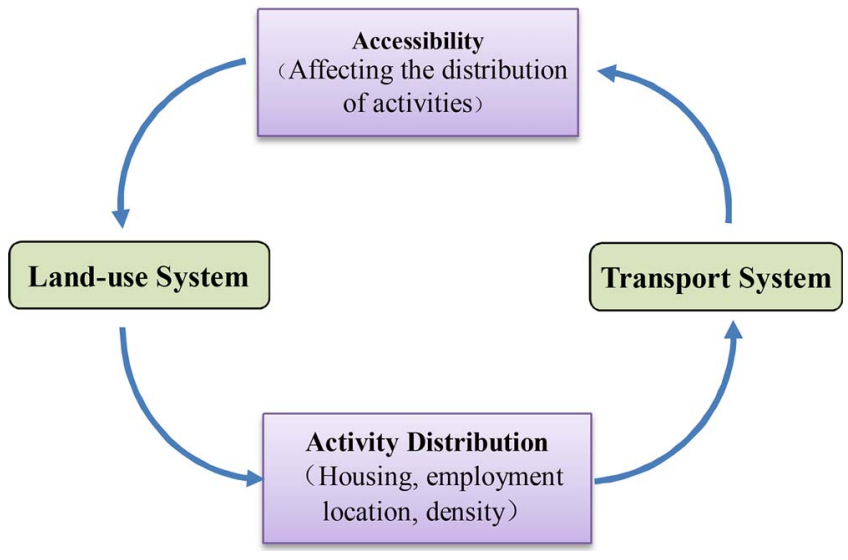

Fig. 1. Feedback cycle of urban system.

it is capable of capturing the complex choice behavior dynamics at the individual level and addressing the locational characteristics. Papers (Jia et al., 2017; Wang, 2014; Weisbrod et al., 1984) verify the choice for identifying the actual travel patterns by accounting for individual spatial behaviors. Given the location pattern of urban activities (residents and employments) and the road network, the transport model calculates the transport cost of traveling between zones (i.e., time cost or economic cost) and the accessibility for each zone by activity as shown by Eq. (1) which is based on work by McFadden (1978),

$A_{i}=\frac{1}{-\lambda} \ln \left\{\sum_{j} W_{j} \exp \left(-\lambda \cdot g_{i j}\right)\right\}$

Here $A_{\mathrm{i}}$ is the accessibility of the zone $i$, the matrix $g$ represents the transport costs between zones calculated using GIS road network, and weight $W_{j}$ is the opportunities or resources in destination zone j. For the household accessibility in a zone, the number of employees by activity is used as its weight indicating the scales of the activity, while for the business accessibility the household population by activity is used as its weight, based on the assumption that a company would optimize a location accessible to its customers and workers. The model shuns the traditional troublesome thresholds settings such as the number of job opportunities within a mile, and is capable of adapting to transport changes. For instance, a new traffic pattern increases local employment, consequently improves the accessibility. The accessibilities are all measured as cost measures. Larger positive values represent high costs, therefore lower accessibilities.

The distribution coefficient $\lambda$ represents the sensitive degree of different traffic patterns for distance change. Normally, different socioeconomic groups are associated with different traffic patterns. At the present stage the model concentrates on urban evolution forecast from the perspective of overall activity distribution and does not classify socio-economic groups, therefore here $\lambda$ is set as a constant.

2.2.2.2. Location utility. The location utility model is developed based on the assumption that the changes of factors cause the urban activities to relocate. The factors considered to affect residential location in this study include the accessibility and location cost calculated based on rent. The Eq. (2) shown below weights the factor change into the change of location utility, which will be further used to calculate the location of activities.

$\Delta V_{t+1, \mathrm{i}}=\theta_{p}^{C}\left(C_{t+1, i}-C_{t i}\right)+\theta_{p}^{A}\left(A_{t+1, i}-A_{t, i}\right)$

Where $\Delta V_{t+1, \mathrm{i}}$ is the change in location utility in zone $i$ in period $\mathrm{t}+1$, $\mathrm{C}_{\mathrm{t}+1, \mathrm{i}}$ is the cost of location in zone $i$ in period $t+1, A_{t+1, i}$ is the accessibility of zone $i$ at time $t+1$. The location cost is the rent per unit multiplied by the average number of units per activities. The change of location utility is calculated by activity and zone. For example, to calculate $\Delta V_{t+1, \mathrm{i}}$ for households, variables $C$ and $A$ are zonal housing cost and household accessibility respectively; to calculate $\Delta V_{t+1, \mathrm{i}}$ for service activities, variable $C$ is average location cost for the activity while the variable $A$ is business accessibility.

2.2.2.3. Residential location model. The main aim of the residential location model is to forecast the number of residents that live in each zone of the study area. The model is developed based on the hypothesis that individuals choose locations maximizing their utility. The consumers of housing spaces value different zones as a function of their location attributes relative to their places of work, education and services, etc. among other factors. Using these assumptions, the probability that households in zone $o$ choose zone $i$ as their place of residence conditioned to location utility and distance is given by Eq. (3). Eq. (3) is an extensive application of random utility theory (McFadden, 1978).

$H(L)_{p o i}^{h}=H(M)_{p o}^{h}\left\{\frac{\exp \left(\Delta V_{p i}^{h}\right) \cdot d_{p o i}^{h}}{\sum_{i} \exp \left(\Delta V_{p i}\right) \cdot d_{p o i}^{h}}\right\}$

Here $H(L)_{p o i}$ is the number of households type $h$ relocated from zone $o$ to zone $i$ and $\Delta V_{p i}{ }^{h}$ is the change of the systematic utility for a household type $\mathrm{h}$ in zone $i$. The system location utility of an activity is a weighted summarization of a set of variables besides transport accessibility, including consumption utility for households/cost for companies, which are estimated based on rent and environmental quality etc. Different applications may differ from each other with respect to the set of variables chosen. The proposed model concentrates on the transport accessibility and consumption utility for households. $H(M)_{p o}{ }^{h}$ is the total number of households (i.e., mobile households) type $h$ that need to be relocated in zone $o$, calculated based on the exogenous ratio of mobile household of the total. $d_{p o i}{ }^{h}$ as a negative logistic function is the distance-deterrence for a household type h from zone $o$ to zone $i$ as shown below,

$d_{p o i}=\frac{\alpha_{p}+\exp \left(\beta_{p} \cdot D_{o i}+k_{p}\right)}{1+\exp \left(\beta_{p} \cdot D_{o i}+k_{p}\right)}$

Where $D_{o i}$ is the distance from zone $o$ to $i$, and $\alpha, \beta, k$ are the coefficients of the distance deterrence function for households in period $p$.

The Eq. (3) is consistent with the economic base theory assuming that any increase in employment has multiplying effects on the population of the urban system.

2.2.2.4. Employment location model. The economic activities location model is used to determine the distribution of employment in different parts of the study area disaggregated into zones. The employment location model is similar in structure to the household location model. By replacing residential terms in Eq. (2) with those of employment, for example, replacing household location utility with business location utility, one can get,

$E(L)_{p o i}^{e}=E(M)_{p o}^{e}\left\{\frac{\exp \left(\Delta V_{p i}^{e}\right) \cdot d_{p o i}^{e}}{\sum_{i} \exp \left(\Delta V_{p i}^{e}\right) \cdot d_{p o i}^{e}}\right\}$

where $E(L)$ is the number of employment relocated from zone $o$ to zone $i$ and $\Delta V_{p i}$ is the change of the systematic utility/attraction of employment in zone i. $E(M)_{p o}$ is the number of mobile employments needed to be relocated in zone $o . d_{p o i}$ is the distance-deterrence from zone $o$ to zone $i$.

2.2.2.5. Real estate rent adjusting model. The activity distributions are partly shaped by the rent cost, whereas the activity distribution change 
in turn results in the change of the rent cost and estate development pattern. After the location model calculates the location of activities, the distributions or densities of the activities change which causes the corresponding rent change. An endogenous rent variable is rarely part of a traditional Lowry model. This model endogenizes the rent calculation by zone, which is then used to calculate the location of activities in next loop. The implicit rent model calculates the average property rents in each zone as a function of the supply and demand, and the previous rents for locating in each zone. The rent, or price of real estate, is the main factor which affects the location utility of activities during iterations. The adjustment of rent is based on the theory that the more demand of floorspace there is in a zone, the higher the rent is (Albouy and Ehrlich, 2014; Mumtaz, 1995). The rent would change by multiplication of demand over supply of floorspace, but should not be less than the minimum rent across the city. For housing the adjustment is,

$r_{p i}^{\prime H}=\max \left\{r(\min )_{p}^{H}, r_{p i}^{H}\left[\frac{\sum_{h} a_{p i}^{H} \cdot H(L)_{p i}}{F(C)_{p i}^{H}}\right]\right\}$

Where $r^{\prime}$ is the new rent of housing floorspace in a zone, $r$ is the previous rent, $a$ is the present density, and $F(C)$ is the current quantity of floorspace that could be occupied. For employment floorspace category the equation is similar with replacement of variables related to household by those of employment.

\subsubsection{BJLUTI model flow diagram}

The employment location model works in a similar way to the residential location model. The algorithm discussed here suits for both residential location model and employment location model.

The location model works based on the hypothesis that workers relocate depending on different zonal characteristics, including the accessibility and consumption utility/profit, obtained from the interaction between the transport and activities location sub-models, and the estate rent of each zone, obtained using the rent estimation model. Depending on the theoretical hypothesis being proposed, multiple interactions and equilibrium formulas can be applied between the different sub-models. The transport accessibilities in the different zones of the study area depend on the distribution of residents and employment activities and the physical transport $g c$ between zones. This also influences the distribution of activities.

The location model is an iterative process. It spatially distributes residents and employments as shown in Fig. 2. The activity distribution and land use policies, along with transport cost, decide the accessibility of each zone which is then used to calculate the location of activities. As a result, the change of activity distribution causes the activity density or estate rent to change. Then the model calculates accessibilities again, and repeats every stage until the stopping criterion is satisfied. The stopping criterion is when the difference of activity distribution between two iterations reaches minimum which is in practice set as zero or a small number. By this way the model output forecast results for the next period $p$, generally next year. Then using the output and the policies of period $p$, the model output the forecast of period $p+1$.

\section{Use of the strategic model}

\subsection{Data and calibration}

In Beijing the newest and longest ring road is 6th Ring Road. Beijing encompasses a total of 18 districts (counties), 14 of which are inside or intersecting with 6th Ring Road. The main urban area is inside 6th ring road. For the advantage of exploring the urban evolution thoroughly we therefore use data at town level for the 14 counties. Four districts Huairou, Miyun, Pinggu, Yanqing outside 6th Ring Road are suburban districts. In total there are 243 zones with the 4 remote districts (counties) inclusive in the Beijing metropolitan area (Fig. 3).

For the corresponding spatial data, the administrative division data at county and town levels is used with all the roads of different classes in Beijing such as highways, provincial roads and county roads. Based on the road networks and estimated speed for different roads, the transport cost between zones as a matrix is calculated.

At present the 6th Census data for 2010 is the most detailed census and is available at town level. The 6th Census categorizes households into 4 types by generation, and provides the zonal demographic data relating to households, workers, the elderly (beyond 60 years old), and children (under 16 years of age). Using the average annual total population growth, the total population estimates for subsequent years can be computed. For employment activities data, survey information is used, which covers almost all companies, organizations, institutes, hospitals and so on, adding up to more than 700,000 records. The survey data also includes the information relating to the scale, location, fixed assets, and employees of each company. This data is plotted to generate a detailed employment distribution for Beijing. According to Beijing business survey data (2010), we categorize business into 8 types. The distribution of each type of activities at town (Jiedao) level is shown in Table 1 ,

The model calibration process is as follows. First, empirical or random values are assigned to the model coefficients according to rule of thumb. Then the values are automatically adjusted based on the correlation of model results with the observation. For example, if a coefficient is positively correlated with the observed results and the observed value is higher, the value of the coefficient will be reduced, and vice versa. This process is repeated until a good fitness is acquired. From the base year 2010, zonal values are predicted overtime. The data projected are compared with the observed data in 2014, showing a correlation of $R^{2}=0.68$. The key coefficient calibration results are shown in Table 2 .

\subsection{Land use policy scenario}

As with most models, the strategy testing process using the proposed model is conducted to forecast the future given a specific scenario. A strategy option is examined using the relevant changes to the model inputs, running the model over time, and analyzing the outputs in terms of urban activity distribution.

The governments in China regulate the behaviors of developers instead of individual residents or enterprise; therefore implicitly guide the households and employment distributions by land use. This study tests the land use policies which are changing more rapidly than the transport system. In the Beijing case study, we set the policy changes based on the land trade data. Every year, the government sells lands to developers to develop floorspace for residential and employment purposes. We gathered the land trades of the latest 5 years that could be acquired (2009-2013) and averaged the amount of floorspace developed each year with respect to land use for each zone, to represent the land use policies for the coming years as shown in Fig. 3. The majority of newly developed land is located outside the city center and along the 6th ring road. This is consistent with the planning policies to develop more centers outside the city center, to reduce the population density and transport congestion of the main urban area. On the other hand the development near the city center is more costly. Relatively speaking, land use for employment is dispersed farther from the city center, which causes the corresponding employment to be distributed in a more dispersed manner.

Besides the land use policies, the urban activity growth variables are specified in the model. According to the average increase in population and employment of recent years, residential population and employment growth rate are set to 0.023 and 0.020 respectively. All the activities other than household are categorized as the employment activity. The corresponding land use (i.e., floorspace development) is 


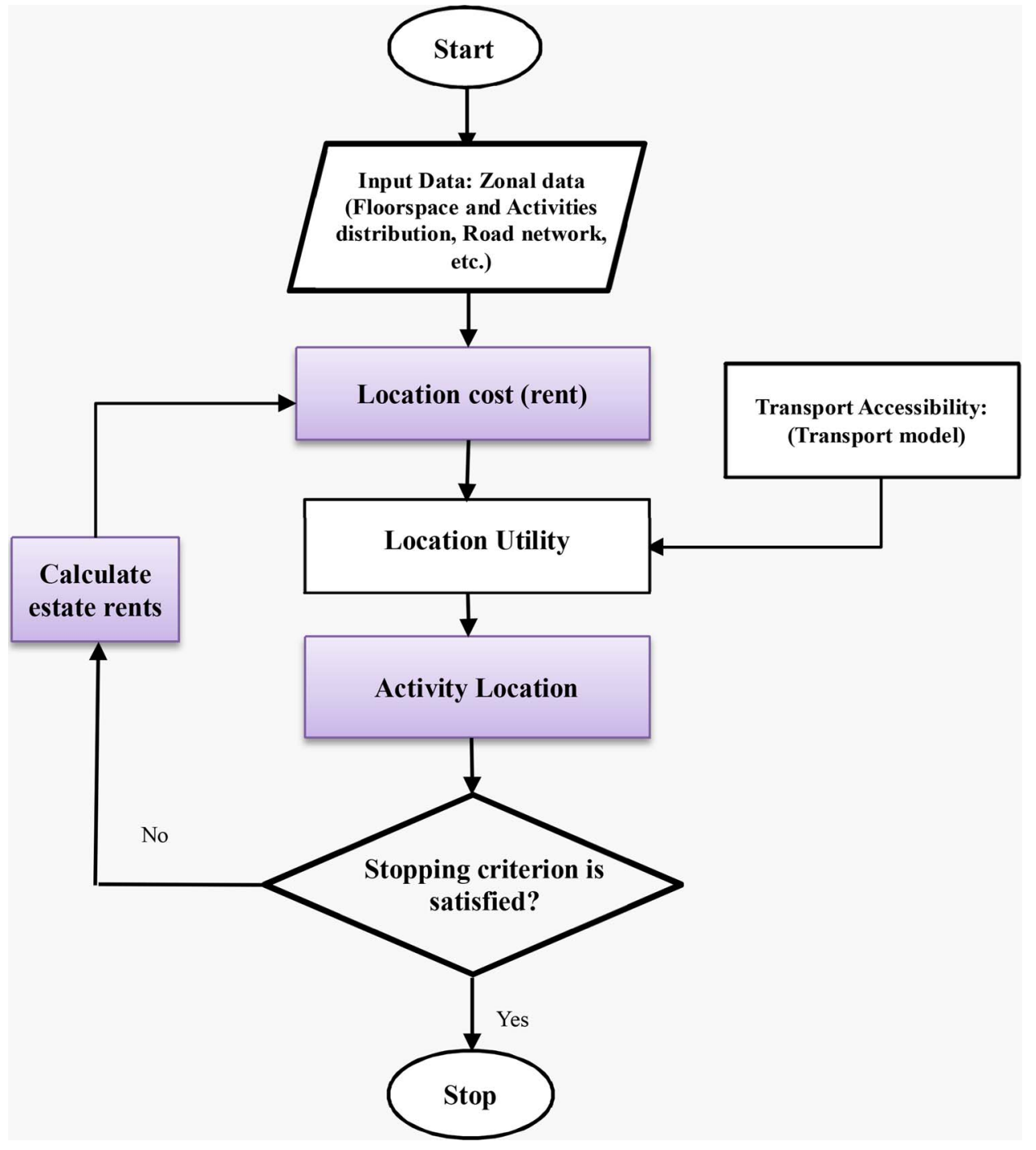

Fig. 2. Flow diagram of the BJLUTI model.

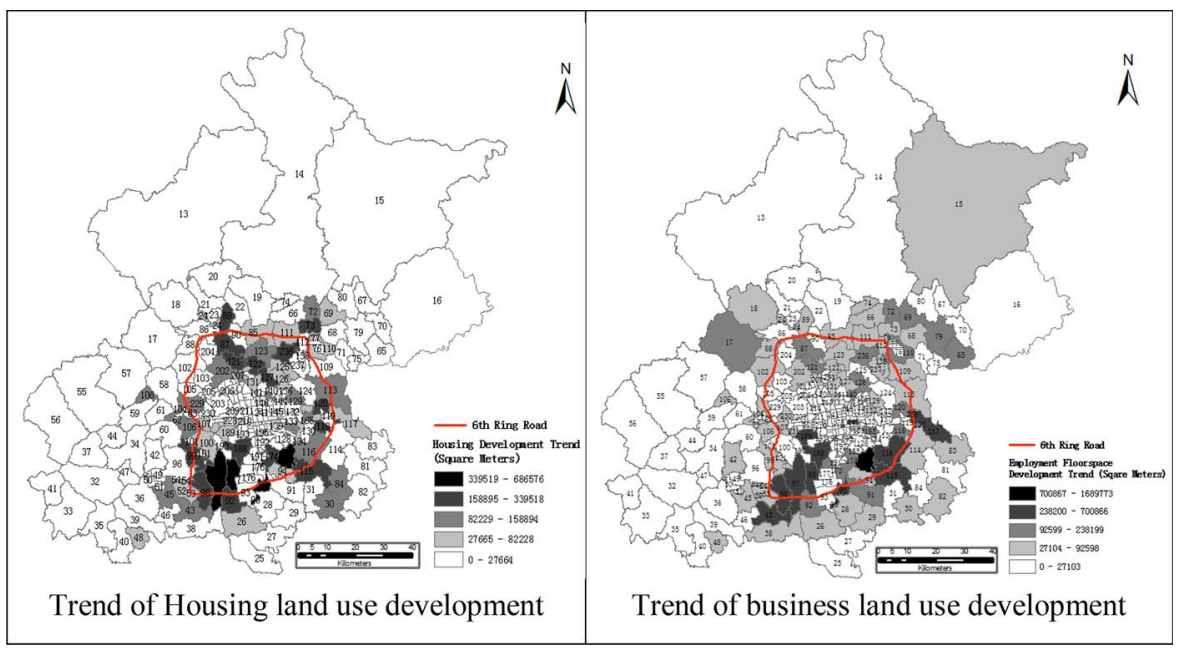

Fig. 3. Land development trend.

categorized into two types: housing and employment floorspace. Land use policy changes are introduced into the proposed model via a sequence of policy files to specify annual changes, i.e., how much of each type of floorspace development will be by zone and year. These are shown in Table 3.

\subsection{Modeling results and analysis}

\subsubsection{Urban activity patterns in 2030}

The data and land use scenario discussed above are used to forecast urban development in Beijing up to 2030. The results are show in Fig. 4 by activity type. 
Table 1

Urban Activity Categorization.

\begin{tabular}{|c|c|c|c|}
\hline Activity type & Activities & Activity description & Composition \\
\hline \multirow[t]{4}{*}{ Household } & Type 1 & Composed of members of the same generation & Worker, Child, Elderly \\
\hline & Type 2 & Composed of members of two generations & Worker, Child, Elderly \\
\hline & Type 3 & Composed of members of 3 generations & Worker, Child, Elderly \\
\hline & Type 4 & Composed of members of 4 or more generations & Worker, Child, Elderly \\
\hline \multirow[t]{8}{*}{ Business (Employment) } & Education & Including all businesses of relating to education & Employees \\
\hline & Industrial & Including businesses about agricultural, industrial, manufacturing production & Employees \\
\hline & Medical & Including businesses about health & Employees \\
\hline & Office & Including businesses about software, government organization, bank, insurance and other monetary sector & Employees \\
\hline & Research & Including businesses about scientific research and geology survey etc. & Employees \\
\hline & retail & Including businesses about wholesale and retail & Employees \\
\hline & Other services & Including other services such as freight, hotel, restaurant, housing renting etc. & Employees \\
\hline & others & $\begin{array}{l}\text { All other business such as entertainment, cultural activities, water conservancy, beauty sport management, } \\
\text { and energy and estate etc. which are not included above. }\end{array}$ & Employees \\
\hline
\end{tabular}

Table 2

Coefficient calibration results

\begin{tabular}{|c|c|c|c|}
\hline \multicolumn{2}{|c|}{ Coefficient } & \multirow{2}{*}{$\frac{\text { values }}{1.0}$} & \multirow{2}{*}{$\begin{array}{l}\text { description } \\
\text { In Eq. (1) }\end{array}$} \\
\hline$\lambda$ & & & \\
\hline \multirow[t]{12}{*}{$\theta_{p}^{C}$} & For household type 1 & 0.00025 & In Eq. (2) \\
\hline & For household type 2 & 0.00033 & \\
\hline & For household type 3 & 0.00093 & \\
\hline & For household type 4 & 0.00065 & \\
\hline & For Education & -0.00139 & \\
\hline & For industrial & -0.00088 & \\
\hline & For medical & -0.00110 & \\
\hline & For office & -0.00104 & \\
\hline & For research & -0.00095 & \\
\hline & For retail & -0.00074 & \\
\hline & For other services & -0.00078 & \\
\hline & For others & -0.00132 & \\
\hline \multirow[t]{12}{*}{$\theta_{p}^{A}$} & For household type 1 & -0.0010 & In Eq. (2) \\
\hline & For household type 2 & -0.0003 & \\
\hline & For household type 3 & -0.0001 & \\
\hline & For household type 4 & -0.0002 & \\
\hline & For Education & -0.0181 & \\
\hline & For industrial & -0.0769 & \\
\hline & For medical & -0.0188 & \\
\hline & For office & -0.103 & \\
\hline & For research & -0.0315 & \\
\hline & For retail & -0.0358 & \\
\hline & For other services & -0.0247 & \\
\hline & For others & -0.0481 & \\
\hline$\alpha$ & & 0.05 & In Eq. (4) \\
\hline$\beta$ & & -0.5 & In Eq. (4) \\
\hline$K$ & & 11.0 & In Eq. (4) \\
\hline
\end{tabular}

Table 3

Policy scenario summarization table.

\begin{tabular}{ll}
\hline Policies & Description \\
\hline Land use & Housing development as trend of past five years. \\
& Business floorspace development as trent of past five years \\
Household & Increase by $2.3 \%$ per year \\
Business & Increase by $2 \%$ per year \\
\hline
\end{tabular}

Urban categorization is subject to the cognition of developers or users and data availability. We aggregate residential population and employment activity respectively and compare the corresponding distribution with that of 2010 with focuses on the change in patterns.

\subsubsection{Overall spatial patterns of population and employment}

3.3.2.1. Population. The projection of residential population of 2030 is shown in Fig. 5. To help analyze the changes of urban activity distribution, we project the main roads in Beijing to the corresponding map below. The ring roads shown in Fig. 5 from outwards to inwards are 6th ring road, 5th ring road and 4th ring road respectively. As the areas of each zones used in Beijing vary from each other, we use the population density to explore the population distribution instead of absolute values. As shown in Fig. 5, in 2030 the majority of residential population is still located inside 4th ring road as in 2010. This is attributed to the fact that the central urban area has been previously developed to a high extent and contains an existing base of employment which leads to the higher household accessibility there. As the residential population increases annually, more people will pour into these zones in addition to the residents already located there. On the other hand, the periphery consists primarily of zones located along the 5th ring road, especially north and east of the 5th ring road. The transport lines are also visibly observed to be an important factor in shaping the distribution of the population, as people are more likely to be located along or near the main roads. Nevertheless, a few zones with higher population density remain separate from the central urban area, such as zone numbers 23, 77 and 51. These zones are the urban areas that are the political centers of suburban counties such as Changping, Fangshan, Shunyi.

Fig. 6 shows the percentage impacts of the land-use policies in 2030 . The maps show that more population will concentrate outside the 4th ring road on the outskirts as the residential population increases annually. This is consistent with the floorspace development distribution pattern as set in the scenario. The more employment floorspace is developed there, the more employments will be generated. Subsequently, the transport accessibility is improved, more residents will locate here.

As shown in Fig. 6, zones with measurable increases in forecasted percentage are located in the outskirt near the 6th ring road. Zones with the highest forecast population density are numbered 89 (Nanshao), 73 (Mapo), 236 (Houshayu), 92 (Beizangcun), 97 (Changyang), 98 (Liangxiang), 173 (Yizhuang). While these zones still do not have enough population density to play as a sub-center role, the trends are point to that direction. The development of these potential sub-centers in the future is in accordance with the government objective of moving to a more polycentric spatial structure to share the service function of central urban area.

3.3.2.2. Employment. The projection employment in 2030 is shown in Fig. 7. In 2030 most employments are forecast to be still located in the central urban area inside the 4th ring road according the current policy scenario. Similar to the residential patterns, it is observed that the employment tends to concentrate along or near the transport corridor which helps increase its accessibility.

Fig. 8 shows the percentage impacts of land use policies, illustrating that the employment impacts of the land use policies are more widely dispersed than the population impacts. A number of zones are observed with a negative percentage change in employment, which means that in 


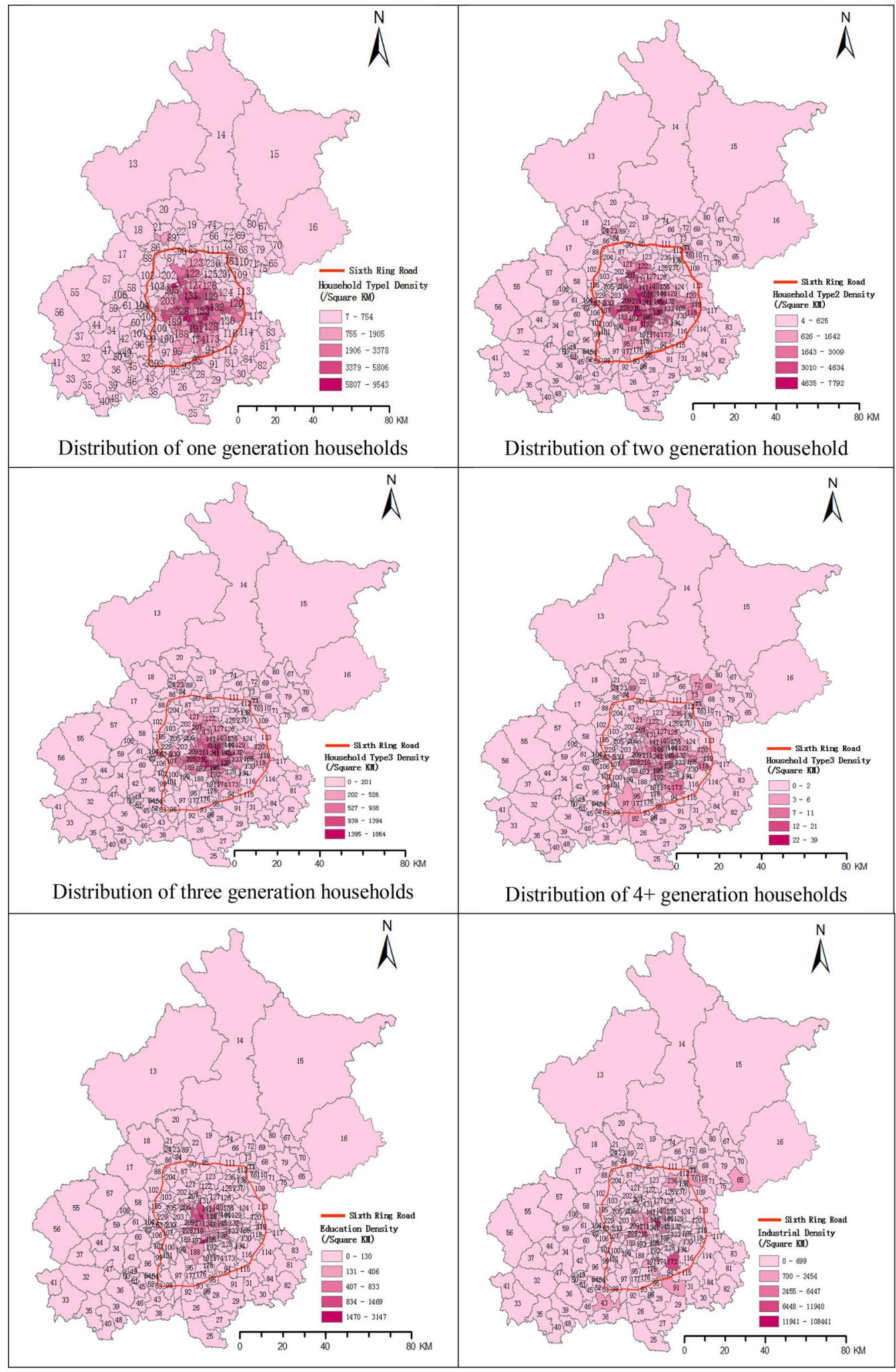

Fig. 4. Forecasted distribution of Employment by type in 2030 .

2030 these zones suffer from loss of employment activity compared with 2010. Almost all the zones of the inner urban area (within the 4th ring road) and the southwest zones have a lower employment density forecasted in 2030. According to the employment land use development set in the scenario, these zones are mainly those with less or no further employment floorspace development. For zones with more floorspace development, the rents will decrease, leading companies to move in from other zones to reduce location cost and enhance location utility, especially from zones with less or no floorspace development.

This will cause companies inside city to move out to the zones with lower rents, and as a result the employment density on outskirts will increase dramatically. The forecasted result is consistent with the aim 


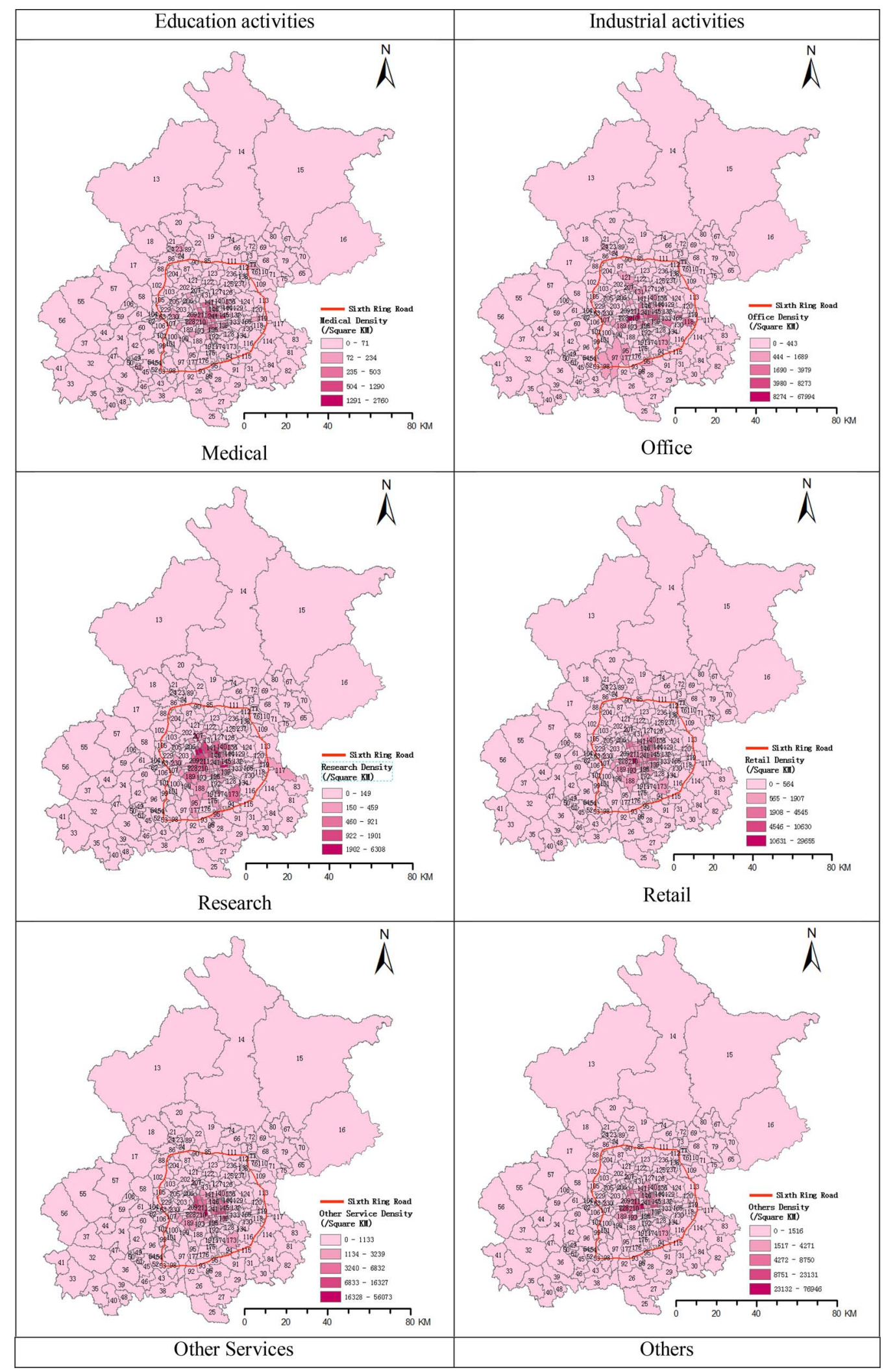

Fig. 4. (continued)

of the urban planning. In fact, companies in every zone would seek a zone to maximum their location utility, so the employment density of some southwest zones will also decrease. The zones with high increase in density are mainly located along the 6th ring road which forms a similar pattern to the employment development by land use policies.
This shows that the government can orient the development of the city, but companies could select their own location freely given the land use pattern planned by the government. The government guides the distribution of urban activities indirectly. 


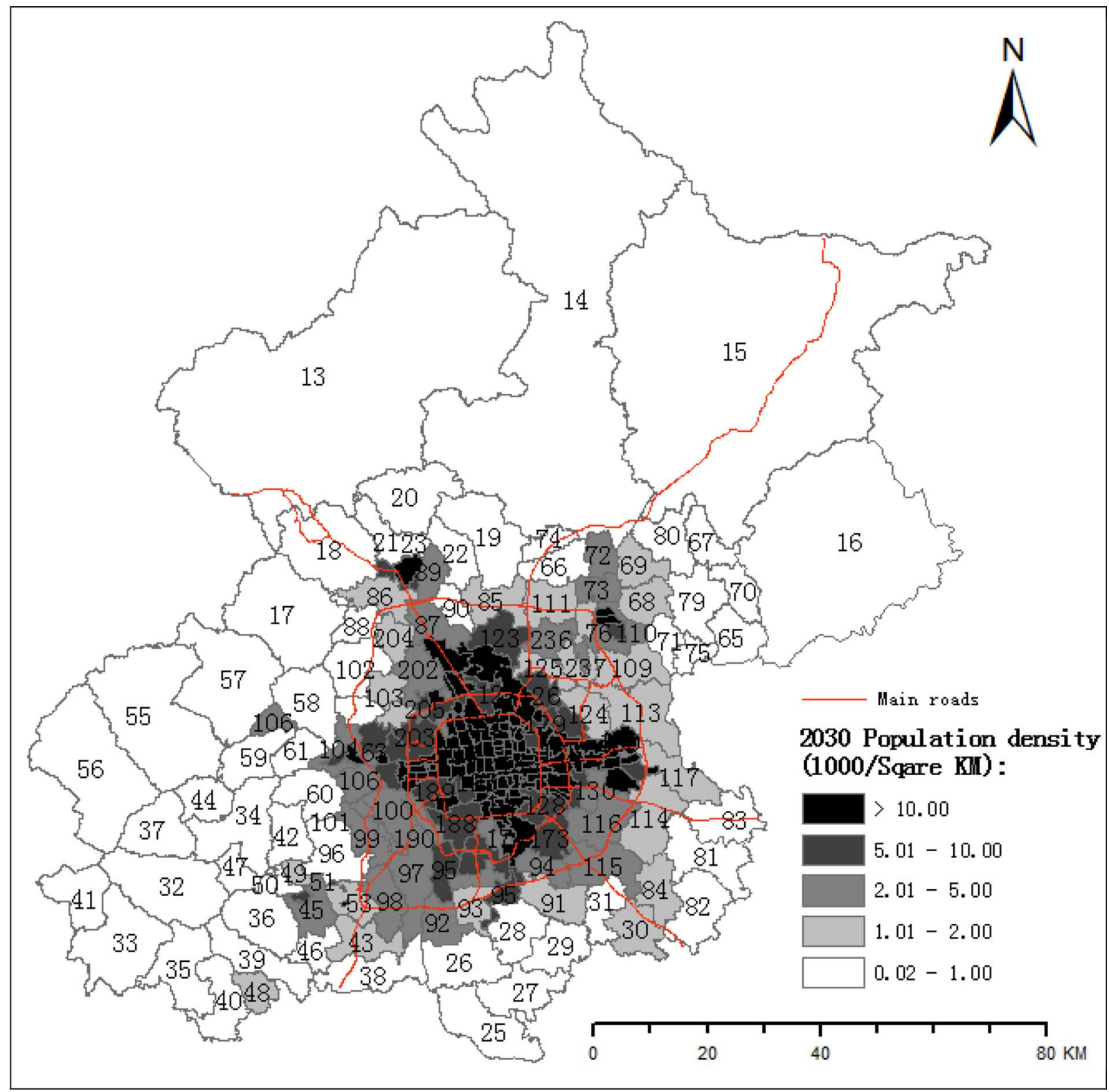

Fig. 5. Forecasted population density in 2030 .

\subsubsection{Comparison between the changes in residents and employments}

By comparing Figs. 6 and 8, one can see that the populations in these zones continues to increase with the annual growth of the total population, and people still tend to concentrate near or inside the central urban area. But the relative proportion of the population in the inner city versus the outskirts decreases over time as more and more residents choose to locate on the outskirts. These population impacts are essentially the effects of improved accessibility to work and service opportunities caused by the relocation of employment activities, together with housing rent changes caused by new housing developments.

Most of the employments are still located inside the central urban area which leads to a higher accessibility than the outside. But for employment, there are quite a few zones whose employment decreases in 2030 in spite of the total annual $2 \%$ employment growth. These zones are comprised of mainly the central zones and those southwest of the central city. According to the proposed model, it is mainly the cost and destination accessibility that determines employment distribution. Companies more likely move out to seek locations with lower rent to reduce their cost if there are more employment floorspace available around the urban area. As a result it could be concluded that in Beijing there is abundant labor for employment, so companies are not necessarily constrained by the accessibility for workers.

The authorities are now implementing strategies to decentralize the residential population by redeploying industries. For the foreseeable future, more and more residents would move out to the outskirts along with employment activity. This proposed model can help quantify the change of population with respect to the employment for each zone.

\section{Discussion}

The nature of the present study is primarily exploratory with regards to the methodology. An activity-based LUTI model is developed. This model estimates changes in the location of population, economic activities, and real estate rents based on the policies and projects introduced by governments related to urban land use and transport. The Beijing case demonstrates that the model can be a useful tool for testing the urban policies towards sustainable urban development. We also recognize that as the urban system is a complex environment our model has limitations which can be strengthened by adding further 


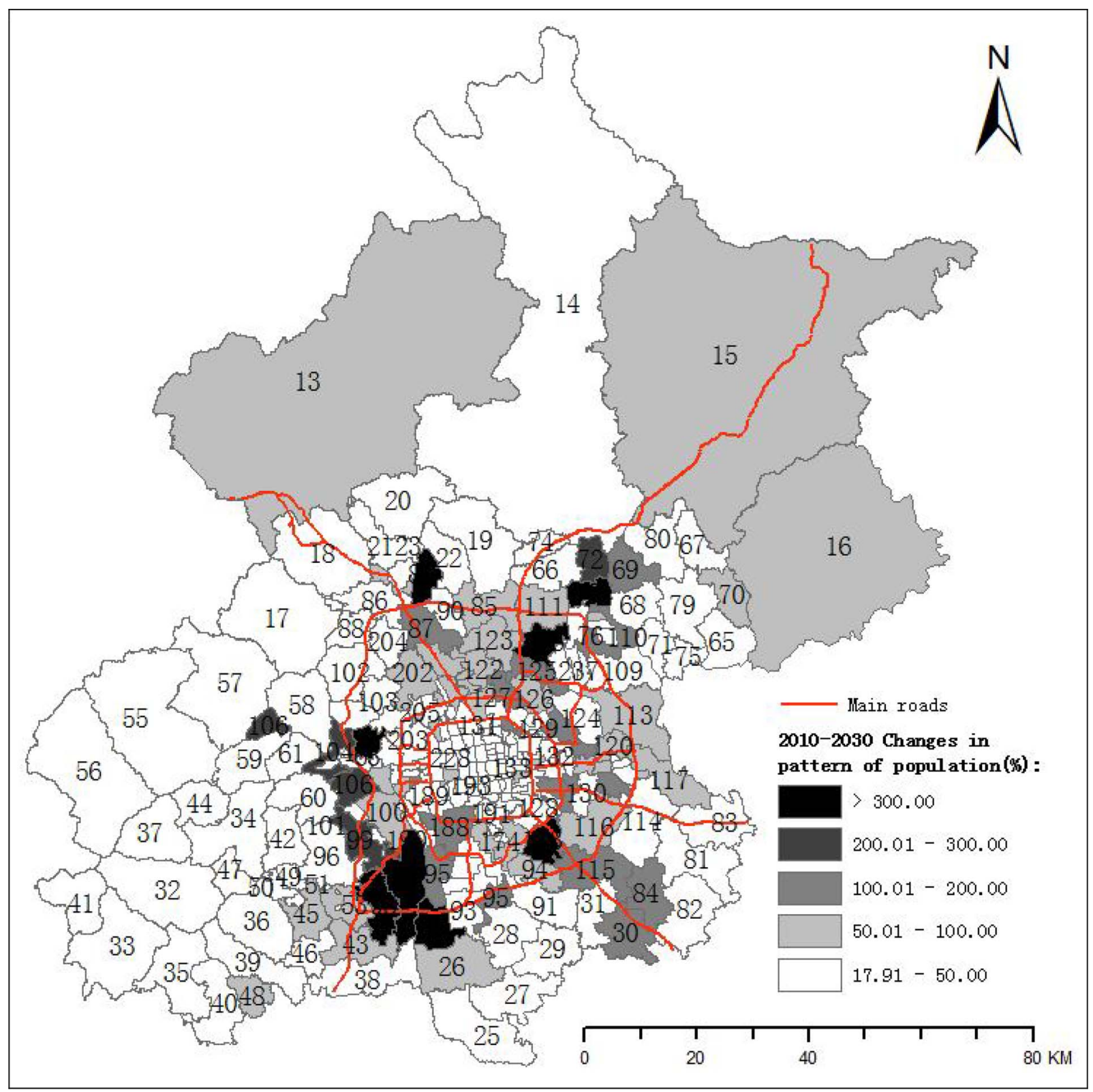

Fig. 6. Forecasted Changes in population (percentage) 2010-2030.

components.

\subsection{The area applied of the model}

In the case study, by assuming the continuation of the recent land use policies in the future, the distributions of different kind of urban activities are forecasted. By comparing it with that of 2010, one can study the change of the spatial pattern of each kind of activity. But the urban system is a complex system which is difficult to forecast accurately since there are uncertain factors including policies. The trend does not represent policies of any authority. As far as the usefulness is concerned, we hold that the relative distribution of the forecast values is of more importance than the absolute values. To support policy decision, the model may serve as a tool to test different impacts under various policy scenarios, which help to identify which is better to achieve the planning goals.

\subsection{Land use scenario and land market}

The aim of this study is to provide a tool to test land use/transport policy scenarios, answering questions such as: "Given the current land use development pattern, what would happen in terms of activity distribution if...?" At present however this LUTI model does not have a land use market sub-model. Land market modeling remains important as land markets are key factors affecting the floorspace development.

In China, the government sells land every year and the developers bid for development. The two parties together determine the urban land use and floorspace development. As floorspace is one of the key factors determining the urban activity distribution, it make sense to develop a sub-model to forecast the floorspace development pattern with respect to the land market.

\subsection{Transport scenario}

We did not introduce any transport scenario as transport systems generally change relatively slowly at this stage. However the model is 


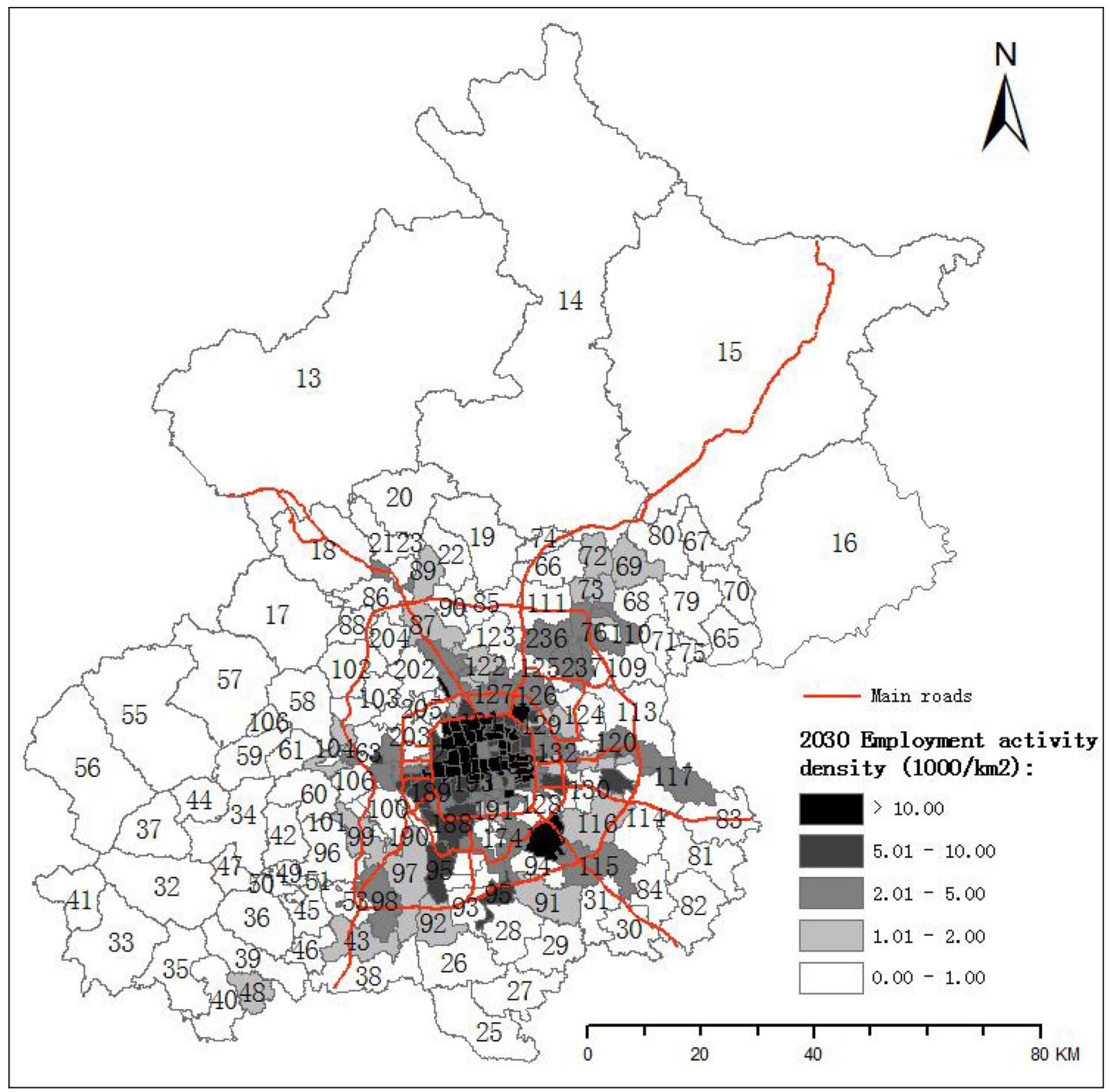

Fig. 7. Forecasted Employment density in 2030.

capable of modeling the impact of transport system change on activity distribution. In Eq. (1) the accessibility is determined by the opportunities (or resources) distribution, $\mathrm{W}$, and transport condition, g, of a city. Based on Lowry model, Wang (1998) simulates the urban population distribution in various urban road network scenarios, for example, sparser network and grid network. However, a more realistic case is to evaluate the impact of transportation network change, such as the developing Xishan tunnel in Beijing. The tunnel connecting the Haidian new district with the Fifth Ring road will be open in 2020. The pilot analysis based on the model reveals a sharp increase at the beginning with a right skewed curve later in population distribution.

Further, in the model the transport cost was computed based on the shortest path between zones without considering transport conditions such as transport mode, congestion and capacity. An intelligent transport sub-model can be developed to calculate the transport cost using existing transport tools such as START or TRIPS. Adding a sophisticated transport model will greatly enhance the BJLUTI's capability to evaluate the impact of new transport interventions.

\subsection{Location utility/attraction estimation}

The consumption utility for household, rent for employment activities and accessibility are used to estimate location utility/attraction in this study. Other factors may affect the attractiveness of a location such as the income level and quality of the housing stock, the quality of the environment and neighborhood amenities in the case of housing. Incorporating these factors into this loosely coupled model is straightforward, but it is important to note that such an endeavor will have to overcome the problem data availability related to these factors.

\subsection{Household composition}

In the model, the accessibility calculated concentrates on the hometo-work trips of workers. There are other household member types to be considered such as home-to-school trips for children, medical service trips for the elderly and home to commercial centers shopping trips. As the location choice of households is influenced by a combination of these factors, the addition of these activity patterns to improve the location utility estimation is important. 


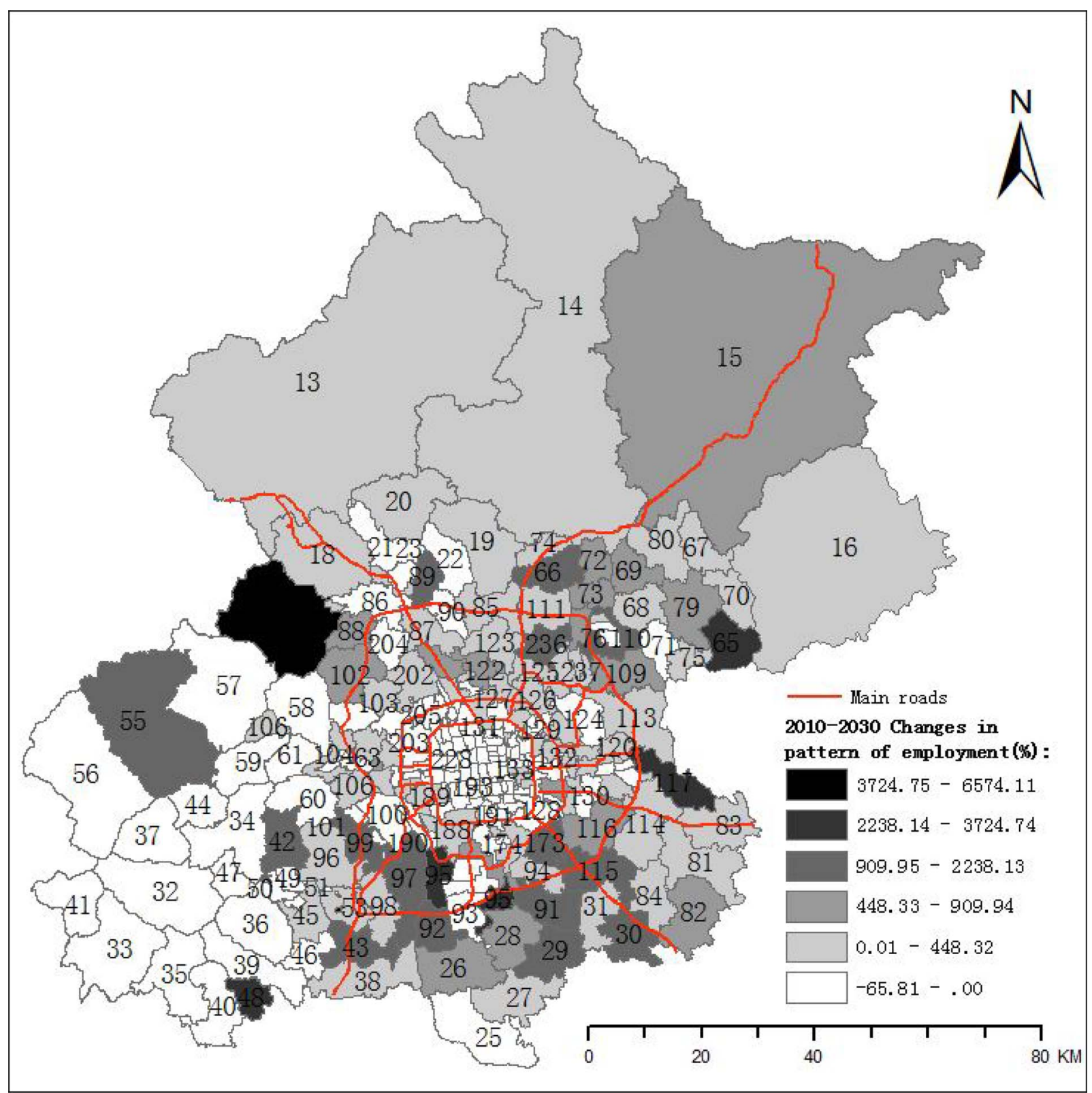

Fig. 8. Changes in employment (percentage) from 2010 to 2030 .

\subsection{Immobility of urban activities}

Normally only the minority of urban activity of a city would change their location; many activities are immobile and would not change their location. The model is used to quantify the overall change of each type of activity by zone, instead of predicting the behavior of any specific activity such as a specific household or company. Certain industries in a city such as mining are nearly immobile. It is unnecessary to predict the variation of the location of these activities. But it is meaningful to specify the mobile percentage for each type of activity and estimate the location.

\section{Conclusion}

This study develops an activity-based Land Use/Transport Interaction (LUTI) model to forecast the urban activity impacts of the land-use policies. Its endogenized and interactive features in residential and employment distribution modeling mark it out from the traditional Lowry models. Both basic sector and non-basic sector distribution in
Lowry model are modeled by activity endogenously in this model. Indirectly, the residential distribution and the employment distribution influence each other and evolve with a dynamic equilibrium. The modeling results confirm that it is the location utility/attraction estimated based on transport accessibility as well as the rent that determines the urban activity distribution. The BJLUTI model developed is subsequently applied to the Beijing case to test the present land use policies. The resultant forecasts show more urban activities would move out to form other centers around the city, which is consistent with the objective of the present urban planning by redeploying industries to decentralize the population spread. The case study shows that in Beijing the transport accessibility plays an important role in determining locations of households, while the location cost represented by rent plays a more important role in determining locations of companies.

The work so far shows that the model can quantify the growth of each type of activity by zone, and provides a useful decision-making support tool to test the urban land use or transport policies. The model can also be applied to other cities in China with minor refinement. This study is the first step in a program of work on the development of LUTI 
models for examining urban spatial evolution and supporting the sustainable development of Chinese cities. Apart from the further work discussed in the discussion section, other work are under development include the model scenarios comparison, further socio-economic group classification and the industry-specific impact on employment distribution study.

\section{Acknowledgments}

This research is under the auspices of granted National Key Research and Development Plan (No. 2016YFC0503506), National Natural Science Foundation of China (No. 41530751). And many thanks go to David Simmonds Consultancy, Cambridge for the permits to use their package DELTA to develop the model. Any opinions expressed are those of the authors and not necessarily those of any other organization or individual. The land-use policies represented in the model have been examined for research purposes and are not necessarily representative of the policies of any authority or agency.

\section{References}

Acheampong, R.A., Silva, E.M., 2015. Land use-transport interaction modeling: a review of the literature and future research directions. Journal of Transport and Land Use 8, 1-28. http://dx.doi.org/10.5198/jtlu.2015.806.

Albouy, D., Ehrlich, G., 2014. Housing Demand and Expenditures: How Rising Rent Levels Affect Behaviour and Costs-of-living over Space and Time. NBER Available at: (Accessed 14 March 2015). http://cba.unl.edu/academic-programs/departments/ economics/about/seminar-series/documents/housingexpenditures.pdf.

Batty, M., 2007. Cities and Complexity: Understanding Cities with Cellular Automata, Agent-Based Models, and Fractals. Cambridge, MA, and London, The MIT press.

Brandi, A., Gori, S., Nigro, M., Petrelli, M., 2014. Development of an integrated transportland use model for the activities relocation in urban areas. Transp. Res. Procedia 3, 374-383.

Deep, S., Saklani, A., 2014. Urban sprawl modeling using cellular automata. Egypt. J. Remote Sens. Space Sci. 17 (2), 179-187.

Ding, C., Lichtenberg, E., 2011. Land and urban economic growth in China. J. Regional Sci. 51, 299-317.

Foot, D.H.S., 1981. Operational Urban Models: An Introduction. Methuen, London, New York.

Gao, J., Wei, Y.D., Chen, W., Chen, J., 2014. Economic transition and urban land expansion in Provincial China. Habitat Int. 44, 461-473.

Garin, R.A., 1966. A matrix formulation of the Lowry model for intrametropolitan activity allocation. J. Am. Inst. Plann. 32, 361-364.

Geurs, K.T., Wee, B.v., 2004. Land-use/transport interaction models as tools for sustainability impact assessment of transport investment: review and research perspectives. Eur. J. Transport Infrast. Res. 4 (3), 333-355.

Gu, C., Pang, H., 2009. Evolution of Chinese urbanization spaces: kernel spatial approach. Sci. Geogr. Sinica 29 (1), 10-14 (in Chinese with English Abstract).

Haregeweyn, N., Fikadu, G., Tsunekawa, A., Tsubo, M., Meshesha, D.T., 2012. The dynamics of urban expansion and its impacts on land use/land cover change and smallscale farmers living near the urban fringe: A case study of Bahir Dar, Ethiopia. Landsc. Urban Plan. 106 (2), 149-157.

Iacono, M., Levinson, D., El-Geneidy, A., 2008. Models of transportation and land use change: a guide to the territory. J. Plann. Lit. 22 (4), 323-340.

Jia, P., Wang, F., Xierali, I.M., 2017. Using a Huff-based model to delineate hospital service areas. Prof. Geogr. 69 (4). http://dx.doi.org/10.1080/00330124.2016. 1266950.

Jing, W., Jianzhong, L., 2011. Study on the urban expansion and model of Lianyungang city based on the multi-temporal remote sensing images. Procedia Environ. Sci. 10, 2159-2164.

Kenji, D., Masanobu, K., 2012. Looking at sustainable urban mobility through a crossassessment model within the framework of land-use and transport integration. IATSS
Res. 35, 62-70.

Lagarias, A., 2012. Urban sprawl simulation linking macro-scale processes to micro-dynamics through cellular automata, an application in Thessaloniki, Greece. Appl. Geogr. 34, 156-160.

Liao, F.H.F., Wei, Y.H.D., 2014. Modeling determinants of urban growth in Dongguan, China: a spatial logistic approach. Stochastic Environ. Res. Risk Assess. 28 (4), 801-816.

Liu, Y., Yue, W., Fan, P., 2011. Spatial determinants of urban land conversion in large Chinese cities: a case of Hangzhou. Environ. Plann. B: Plann. Design 38 (4), 706-725.

Liu, Z.F., He, C., Zhang, Q.F., Huang, Q.X., 2012. Extracting they dynamics of urban expansion in China using DMSP-OLS nighttime light data from 1992 to 2008. Landsc. Urban Plan. 106, 62-72.

Long, Y., Han, H., Lai, S.-K., Mao, Q., 2013. Urban growth boundaries of the Beijing Metropolitan Area: comparison of simulation and artwork. Cities 31, 337-348.

Lowry, I.S., 1964. A Model of Metropolis [M] RM-4035-RC. Santa Monica CA, Rand Corp.

McFadden, D., et al., 1978. Modelling the choice of residential location. In: Karlquist, A. (Ed.), Spatial Interaction Theory and Residential Location, pp. 75-96 (Amsterdam: North Holland).

Mohammed, A., 2014. Toward integrated land use and transport planning in fast-growing cities: The case of Jeddah, Saudi Arabia. Habit. Int. 41, 205-215.

Mumtaz, B., 1995. Meeting the Demand for Housing, A Model for Establishing Affordability Parameters. The Bartlett Development Planning Unit Available at: (Accessed 14 March 2015). www.ucl.ac.uk/silva/bartlett/dpu/publications/dpupaper-73.

Pierlugi, C., Angel Ibeans, I., Luigi, D.O., Ruben, C., 2013. LUTI model for the metropolitan area of santander. Urban Plan. Dev. 139 (3), 153-165.

Powers, Ryan P., Hermosilla, Txomin, Coops, Nicholas C., Chen, Gang, 2015. Remote Sensing and object-based techniques for mapping fine-scale industrial disturbances. Int. J. Appl. Earth Observ. Geoinfor. 34, 51-57.

Reisi, M., Lu, A., Rajabifard, A., Ngo, T., 2016. Land- planning: implications for transport sustainability. Land Use Policy 50, 252-261.

Simmonds, D., Feldman, O., 2011. Alternative approaches to spatial modelling. Res Transp. Econ. 31 (1), 2-11.

Timmermans, H., 2003. The saga of integrated land use-Transport modeling: how many more dreams before we wake up? In: 10th International Conference on Travel Behaviour Research Lucerne. 10-15. August 2003.

Torrens, P.M., 2000. How Land-use Transportation Models Work. Centre for Advanced Spatial Analysis, London.

Verburg, P.H., Van De Steeg, J., Veldkamp, A., Willemen, L., 2009. From land cover change to land function dynamics: a major challenge to improve land characterization. J. Environ. Manage. 90, 1327-1335.

Waddell, P., Ulfarsson, G.F., Franklin, J.P., Lobb, J., 2007. Incorporating land use in metropolitan transportation planning. Transp. Res. Part A: Policy Pract. 41 (5), 382-410.

Wang, H., He, S., Liu, Xingjian, Dai, Lan, Pan, Peng, Hong, Song, Zhang, Wenting, 2013. Simulating urban expansion using a cloud-based cellular automata model: A case study of Jiangxia, Wuhan, China. Landsc. Urban Plann. 110, 99-112.

Wang, F., 1998. Urban population distribution with various road networks: a simulation approach. Environ. Plann. B: Urban Anal. City Sci. 20, 265-278.

Wang, F., 2014. Quantitative Methods and Socio-Economic Applications in GIS, second edition ed. CRC Press (ISBN: 978-1-4665-8472-3).

Wegener, M., 2004. Overview of land-use transport models. In: Hensher, D.A., Button, K. (Eds.), Transport Geography and Spatial Systems. Elsevier, Oxford, pp. 127-146.

Wei, Y.H.D., 2012. Restructuring for growth in urban China: transitional institutions, urban development: and spatial transformation. Habitat Int. 36, 396-405.

Weisbrod, G.E., Parcells, R.J., Kern, C., 1984. A disaggregate model for predicting shopping area market attraction. J. Market. 60, 65-83.

Wilson, A.G., 1998. Land-use/transport interaction models - past and future. J. Transp. Econ. Policy 32 (1998), 3-26.

Zeng, C., Liu, Y., Stein, A., Jiao, L., 2015. Characterization and spatial modeling of urban sprawl in the Wuhan Metropolitan Area, China. Int. J. Appl. Earth Observ. Geoinf. 34 10-24.

Zhang, T., 2000. Land market forces and government's role in sprawl: the case of China. Cities 17, 123-135.

Zondag, B., de Bok, M., Geurs, K.T., Molenwijk, E., 2015. Accessibility modeling and evaluation: the TIGRIS XI land-use and transport interaction model for the Netherlands. Comput. Environ. Urban Syst. 49, 115-125. 